\title{
Üriner Sistem Taş Hastalığında Randal Plaklarının Önemi
}

\author{
Tayfun Şahinkanat
}

Kahramanmaraş Sütçüimam Üniversitesi, Üroloji Anabilim Dalı, Kahramanmaraş

\section{Giriş}

Tayat boyu yaklaşık olarak kadınların \%5'inde, erkeklerin 1 ise \%12'sinde böbrek taşı gelişmektedir (1). Endoskopik böbrek içi haritalandırma ve papilla ucu biyopsi çalışmaları, Randal plaklarının bu taşların büyük çoğunluğunun (idiyopatik kalsiyum oksalat taşlarının) oluşum sürecinin temelinde önemli bir rol oynadığını göstermektedir. Randal plaklarının üriner sistem taş hastalığındaki önemini anlamak için bu olaylar dizisine ve taş plak ilişkisine daha yakından bakılmalıdır.

Bugün için böbrek taşı oluşumunda üç yolaktan bahsedilmektedir. Şekil 1'de gösterildiği üzere ilk yolak (1) nefron boyunca (asteriks) veya böbrek toplayıcı sistemi içinde meydana gelen "serbest partikül" oluşumunu, ikinci yolak ise (2) hücresel hasarın olduğu nefron lümeninde kristal yapışma ve büyümesi ile sonuçlanacak kristal çekirdekçik oluşumunu gerektirir. Üçüncü yolak (3) renal papillayı örten normal ürotelyumun kaybını takiben idrardaki kristallerin interstisyel kalsiyum fosfat (CaP) kristal depolarına (Randal plağı) tutunduğunu ileri sürer.(2)

\section{Taş Oluşumunda Randal Plak Hipotezi}

Böbrek taşlarının büyük çoğunluğu, kalsiyum taşlarının yaklaşık \%80'ini oluşturan kalsiyum oksalat ( $\mathrm{CaOx}$ ) veya $\mathrm{CaP}$ taşlarıdır. Randal tarafından 1937'de ilk tanımlandığından

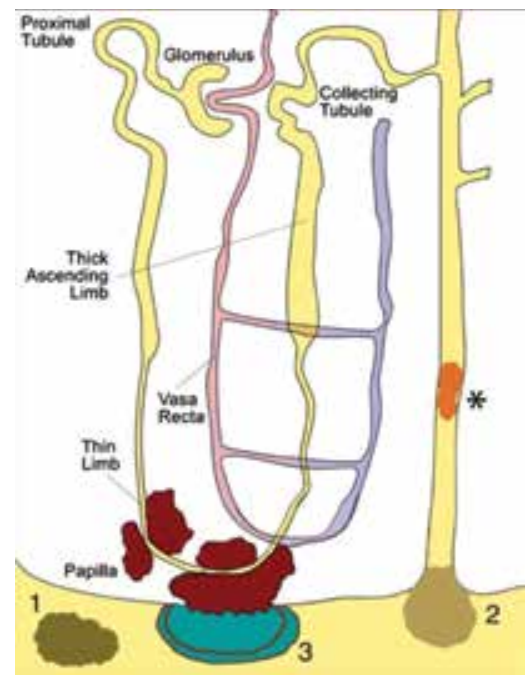

Şekil 1: Böbrek taş oluşum yolakları

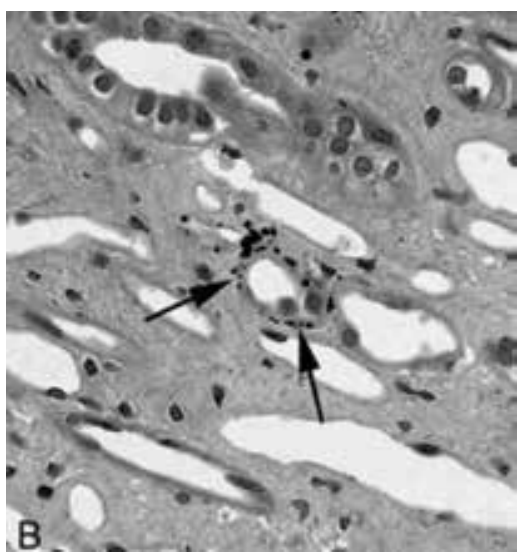

Şekil 2: Işık mikroskopisi kristal depolanmanın (oklar) başlangıç bölgesinin Henle ince kolunun bazal membranı olduğunu göstermektedir. Bu birbirinden ayrı olan depositler interstisyel alanda toplanırlar

bugüne, $\mathrm{CaOx}$ taşlarının renal papillanın interstisyel apatit depolanması içeren bölgesine tutunarak büyüdüğü bilinmektedir (3). Randal plağı, Henle' nin ince kolu bazal membranında oluşmaya başlayan, önce interstisyuma ve en sonunda subüretelyal alana ilerleyen apatit yapısındaki CaP'ın medüller ve papiller alanda ki depolanmasıdır (4) (Şekil 2). Depositlerin başlangıç yerinin Henle ince kolunun bazal membranı olması sürpriz değildir; bu bölge Ca ve $\mathrm{P}^{\prime}{ }_{1}$ kendine çekecek elektrostatik özelliğe sahip mukopolisakkaritten yoğun olan kollajenden oluşur (5). Plak oluşumu kollajen matriks içindeki kristalizasyona bir örnektir. Ayrıca Henle ince kolu içindeki sıvı CaP kristalizasyonunu başlatmak için çok uygundur (6). Bu hipotez, renal papillayı kaplayan sağlam ürotelyumun kaybının (Şeik 1; 3) interstisyel CaP kristal depolarının (Randal plağı) idrar ile temasa geçmesine neden olacağına, böylece idrardaki kristallerin aşırı büyüme gösterecek şekilde interstisyel plak üzerine tutunabileceğini ve bu durumun fikse taş oluşumuna neden olabileceğini ileri sürer (Şekil 2 ve 3) (2). Bu teori açıkça interstisyel plak bölgelerinin başlangıç lezyonları olduğunu belirtmektedir. Randal 1154 çift kadavra böbrek papillasını incelediği tarihsel çalışmasında, papilla uçlarında 'masum' görünümlü krem renginde subepitelyal intertisyel kristal plakaların var olduğunu göstermiştir (3). Ancak Randal, teknik yetersizlikler ve incelediği böbreklerin klinik verileri hakkında yeterli bilgisinin olmaması nedeniyle hatalı bir şekilde tüm taşların kendi hipotezine göre oluştuğunu ileri sürmüştür. 


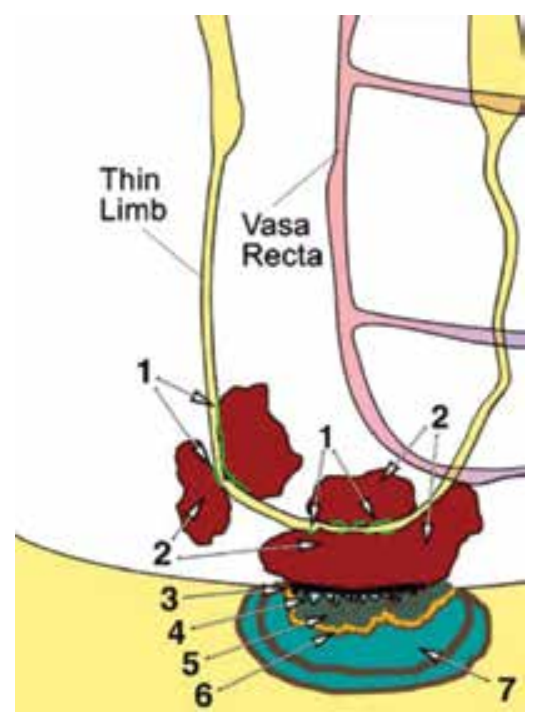

Şekil 3: İdiyopatik $\mathrm{CaOx}$ taş hastalarındaki taş oluşum şeması. 1) Henle ince kolu bazal mambranında apatite deposit gelişimi; 2) bu apatite depositler interstisyel alana yayılımı ve matrikse gömülerek Randal plağı olarak adlandırılan interstisyel plak adalarının oluşumu; 3) ürotelyal kılıfın kaybı nedeniyle interstisyel plakların idrar ile temas etmesi; 4) idrar protein ve iyonlarının plak yüzeyini kaplamaları; 5) interstisyel plağın tepesinde amorf apatite tabakası oluşumu ve bu yeni mineral tabaka idrar matriks molekülleri ile örtülmesi; 6) matriks kaplı biyolojik apatite tabakasının amorf apatite dönüşümü;

7) apatite ve $\mathrm{CaOx}$ tabakasının oluşumu son aşamada bu küçük taşın dış kısmında sadece CaoX bulunur (2)

Evan ve ark.'larının gözlemlerine göre de; plak subepitelyal yerleşimliydi ve dokuya yapışı taşın alınmasından dolayı oluşan çukur bölge hariç pürüzsüz bir dış yüzeye sahipti (7). Yasue yöntemi ile boyalı papiller biyopsi materyalinin, 1şık mikroskopi incelemesi minerallerin ilk toplandığı yerin Henle ince kolunun bazal membranı altındaki özel bir bölgede olduğu ortaya konulmuştur. Ayrıca hiçbir idiyopatik $\mathrm{CaOx}$ taş hastasının papiller biyopsisinde plak etrafında hücre hasarına, enflamasyona, interstisyel fibrozise veya intratubuler kristal materyal varlığına ait herhangi bir bulguya rastlanmamıştır (7).

\section{Taş-Plak Birleșim Yerinin Ultrastruktural Özellikleri}

Taş-plak birleşim yerinin ultrastruktural yapısının incelenmesinde, plak ile idrar alanının keskin bir sınır ile ayrıldığı görülmektedir (Şekil 4 A, panelin alt yarısı) (8). Plak sınırı çok tabakalı kurdele görünümüne sahiptir (Şekil 4 B ve C'deki A harfi). Şekil 4 B'de "ok başlar"1 ile gösterilen büyük bir kristal kütlesinin, daha küçük kristal kütlelerinin (Şekil 4 C;asteriks) birbiri ile birleşmeleri sonucu oluştuğunun da gösterdiği gibi, idrar içeriğinin plak ile teması taş oluşumunun temelidir.

\section{Ara Yüzey Matriksinin İmmunohistokimyasal Yapısı}

Evan ve ark'ları, idrar orijinli moleküllerin korunaksız plağın üzerini kapladığını, bu moleküllerin taşın temelini oluşturduklarını ileri sürmektedirler (2). Eğer bu görüş

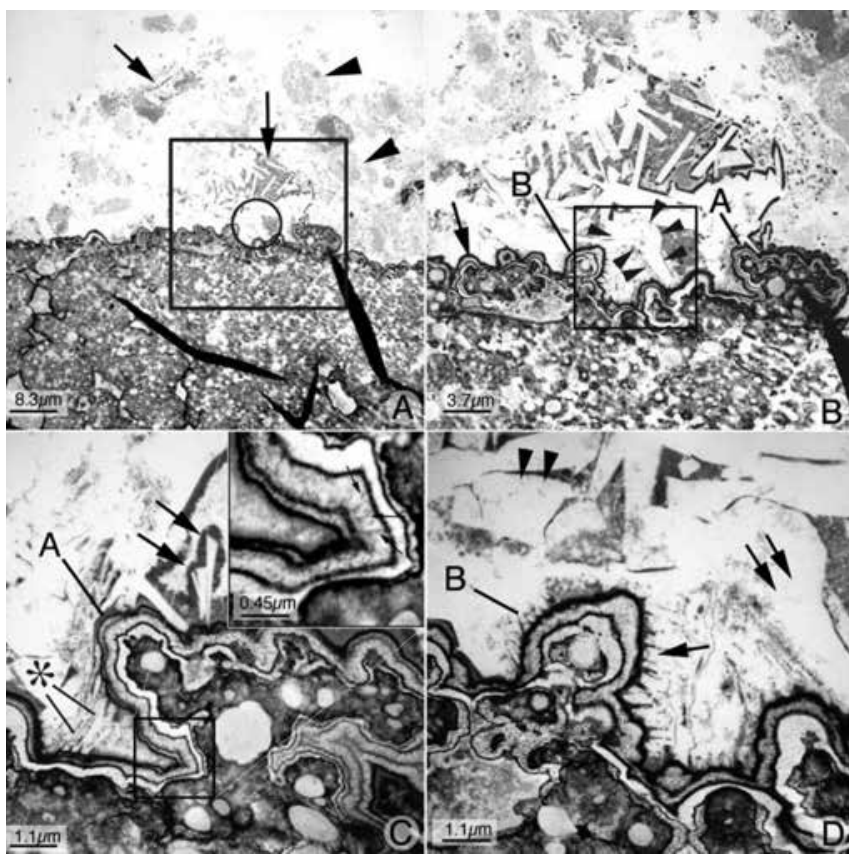

Şekil 4: Taşın plağa tutunma bölgesinin transmission elektron mikroskopi görüntüleri

doğru ise plakta bulunmayan, idrarın bir bileşeni olan Tamm-Horsfall proteinin taş-plak ara yüzeyinin üriner sistem kısmındaki mineral yapılar arasında bulunması gerekecektir. Tamm-Horsfall proteini beklendiği gibi taş mineralinde ve taş-doku ara yüzeyinde bulunurken, doku plağına geçmediği görülmüştür (8). Ayrıca, normalde hem idrar hem de plakta bulunan osteopontinin de; hem taşın içinde hem de plakta belirlenmesi gerekecektir. Osteopontinin de beklendiği gibi, hem taşın mineral yapısında olduğu hem de Randal plağının doku minerali içine doğru hafifçe uzanım gösterdiği belirlenmiştir (8).

\section{Randal Plağı İdiyopatik CaOx Taş Oluşumunda Özgün Bir Yapıdır}

\section{Endoskopik ve Histolojik Gözlemler}

Bazı araştırmacılar Randal plaklarının böbreğin özgün anatomik bölgesi papilladan geliştiği hipotezini test etmek ve taş oluşum patofizyolojisini ortaya koymak için, perkütan nefrolitotripsi (PNL) sırasında papiller biyopsi alınmasını içeren digital endoskopik çalışmalar planlamışlardır. Evan ve ark.'ları 15 idiyopatik $\mathrm{CaOx}$ taş hastası, 4 obezite bypass cerrahisi geçirmiş hasta ve 4 taş dışı nefrektomi yapılan (aile taş anamnezi negatif) hasta olmak üzere toplam 19 hastadan sirasiyla 43, 19 ve 9 adet endoskopik olarak papilla biyopsisi aldıkları çalışmalarında, idiyopatik $\mathrm{CaOx}$ taş hastalarının hepsinde papilla ucunda, beyazımsı, düzensiz kenarlı Randal plak varlığ 1 belirlenirken, bypass cerrahisi geçiren ve nefrektomi grubundaki olguların hiç birinde Randal plağına rastlanmamiştır (9).

Eğer $\mathrm{CaOx}$ taşları tutunmak ve klinik olarak anlamlı boyutlara ulaşabilmek için Randal plaklarına ihtiyaç duyuyorlarsa, taş yükü fazla olan hasta grubunda, taş yük ile orantılı olarak Randal plak sayısı ve veya yüzey alan hacminin de fazla olmasını beklemek mantıklı olacaktır. Linnes ve ark.'ları 78 PNL uyguladıkları hastanın papiller Randal 
Tablo 1: Taş hastalarında görülen farklı histopatolojik değişikler

\begin{tabular}{lccc}
\hline Fenotip & Taşlar & İterstisyum & IMTK BK \\
\hline İKTH & CaOx & Yoğun plak & - \\
Obezite & CaOx & Plaksız & Apatit tıkaç \\
Bypass & Brushite & Plak & Apatit tıkaç \\
CaP & Apatit & Plak & Apatit tıkaç \\
& Apatit & Plak & Apatit tıkaç \\
dRTA & Sistin & N plak & Apatit/sistin \\
Sistinüri & CaOx Apatit & Yoğun plak & Apatit tıkaç \\
Primer & & & \\
hiperparatirodi & & & \\
\hline
\end{tabular}

N plak: \%0,5; Plak:\%1; Yoğun plak: \%7. İKTH: idoyopatik CaOx taş hastası. İMTK: inner medullar toplayıcı kanal. BK: Bellini kanalı. dRTA: distal reanal tubuler asidoz.

plak haritasını çıkarttıkları ve papiller biyopsi aldıkları çalışmalarında hastalardaki Randal plak ve (toplayıcı kanal veya Bellini kanallarını tutan) tubuler tıkaç sıklığının taş tipi ve yükü ile korelasyonunu araştırmışlardır (10). Hastaların \%99'unun ( $n=77 / 78)$ en az bir papiller plağa ve beşte birinin de anlamlı büyüklükte tubuler tıkaça (yüzey alanı>\%1) sahip oldukları tespit edilmiştir (Tablo 1). İdiyopatik CaOx taş hastaları en geniş plak yüzey alanına $(\% 3,4 \pm \% 4)$ sahip iken, bu oran en az ürik asit taşlılarda görülmüş (\%1,7士\%1,5) (10).

Taş sayısı fazla, hiperkalsiürik, idrar hacmi düşük olan hastalarda plak yüzey alanının, olmayanlardan daha fazla olduğu belirlenmiştir $(11,12)$. Plak miktarı idrar kalsiyum seviyesi ile doğru, idrar hacmi ile ters orantılıdır $(10,12)$. Kuo ve ark.'ları 14 idyopatik $\mathrm{CaOx}$ taş hastası ve 4 klinik ve aile taş anamnezi negatif olan kontrol hastasını değerlendirmeye aldıkları çalışmalarında ortalama plak yüzey alanının (\%7.4 vs. $\% 0.5, \mathrm{P}=0.012$ ) ve papilla başına düşen ortalama plak sayısının (\%7.6 vs. \%0.6, $\mathrm{P}=0.011) \mathrm{CaOx}$ taş hasta grubunda daha yüksek olduğunu hesaplamışlardır (12). İlginç bir şekilde obezite bypass cerrahisi geçirmiş $\mathrm{CaOx}$ taş hastalarında ise bu tür plaklara rastlanılmamaktadır (9). Bu hasta grubunun idrar hacmi fazla, idrar kalsiyum atılımı normal aralıkta ve idrar $\mathrm{pH}^{\prime} 1$ asidiktir; dolayısı ile plak oluşumunda idrar hacmi ve atılan kalsiyum miktarının idrar $\mathrm{pH}^{\prime}$ na göre daha önemli olduğu söylenebilir. Brushite (kalsiyum mono-hidrojen fosfat) taş hastalarında da; idyopatik hiperkalsiüri ile birlikte plaklar izlenmektedir (13). Ancak bu hasta grubunda taşlar interstisyel plaklar üzerinde gelişmemektedir, burada ki plak Randal'ın Tip II olarak tanımladığı sarı renkli, yılanvari kıvrılan plaktır (11).

Görüldüğü üzere bu plaklar, üriner sistem taş hastalarının önemli bir kısmında taş oluşum sürecinin ilk ve temel basamağıdır.

\section{İdyopatik CaOx Taş Hastalarında Taşlar Plağa Tutunmuşlardır}

CaOx taşlarının yaklaşık \%75'ini oluşturan idyopatik kalsiyum taş hastaları'nda taşlar Randal plağına tutunarak oluşur (Şekil 5).

Diğer böbrek taşı tiplerinde taş gelişimi için tutunma bölgesi olarak hizmet eden tıkaçlar, Bellini ve meduller toplayıcı kanallar boyunca oluşmaktadır. Tıkaçlara tutunarak Bellini kanalından toplayıcı sisteme uzanan taşların hiçbiri $\mathrm{CaOx}$ değil, hepsi apatite taşlarıdır. Obezite cerrahisi geçirmiş ve sistinürik hasta gruplarında ise taşların serbest çözelti içinde oluştuğu görülmüştür. Sadece primer hiperparatirodi hasta grubunda taş oluşumu hem dokuya hem de tıkaçlara tutu-

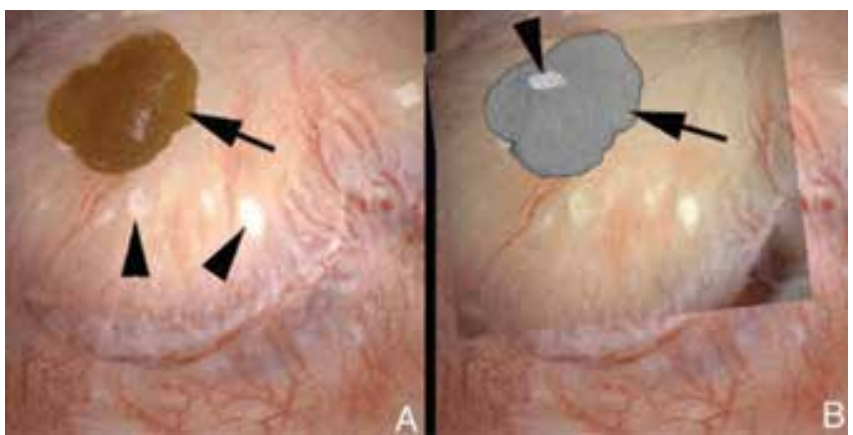

Şekil 5: Doku, taş, plak ve yapışma bölgesi arasındaki ilişki; a) İdiyopatik $\mathrm{CaOx}$ taş hastasının papillasındaki $\mathrm{CaOx}$ taşının endoskopik görüntüsü (ok). Randal plağına ait bölgeler (ok başı) kolaylıkla görülmektedir. b) Taş çıkarıldıktan sonra taş sınırının izdüşümü (ok) gösterilmekte olup, CaP bölgesi kolaylıkla görülmektedir (ok başı). Böylece her taşın Randal plak bölgesine yapışık olduğu belgelenmiş olmaktadır (2)

nan $\mathrm{CaOx}$ taşları şeklinde gerçekleşmektedir (2).

Evan ve ark.'ları PNL uyguladıkları hastalarda yürüttükleri çalışmalarında, dokuya yapışık olan idyopatik CaOx taşlarının bir plağa tutunup tutunmadıklarını araştırmışlardır (8). Yazarlar demineralizasyon ve kesitleme işlemi sonrası, taşın konkav yüzeyinde yer alan eski yapışma bölgesindeki plağ görüntülemişlerdir. Şekil 6'da demineralizasyon sonras1 papillar bölgedeki taş-doku kompleksi görülmektedir.

Evan ve ark'ları, 23 idiyopatik CaOx taş hastasında (24 böbrek) endoskopik olarak toplam 172 papillayı incelemiş ve bunların 156'sında (\%91) plak olduğunu gözlemlemişlerdir (11). Ek olarak bu hastaların 11'inde (\%48) 49 taşın bu plaklara yapışık olduğunu belirlemişlerdir (11). Miller ve ark.'ları da; dokuz hastadaki (12 böbrek) çoğunluğu $\mathrm{CaOx}$ olan toplam 115 taşın endoskopik değerlendirilmesinde, 90 taşın papillaya, bunların 81'nin de plağa yapışık olduğunu 8 olgudan ise emin olamadıklarını bildirmişlerdir (14).

Araştırmacılar verilere dayanarak plağa tutunan taş sayısı için "son nokta tahmin oranı"'nı \%75.4 (\%95 güven aralığı; 0,575 - 0,933) olarak belirlemişler ve bu değeri idyopatik $\mathrm{CaOx}$ taş hastalarında taşların plağa tutunarak geliştiği şeklinde yorumlamışlardır (14).Yazarlar ayrıca üriner sistemde serbest halde gördükleri 25 taştan, kaybolduğu için değerlendirilemeyen 4'ü dışındaki diğer 12 taşta bir zamanlar dokuya yapışık olduklarına dair morfolojik kanitlar tespit ederken, mikro-BT ile incelenen 9 taşın analizlerinde de bunların iç kısımlarında 


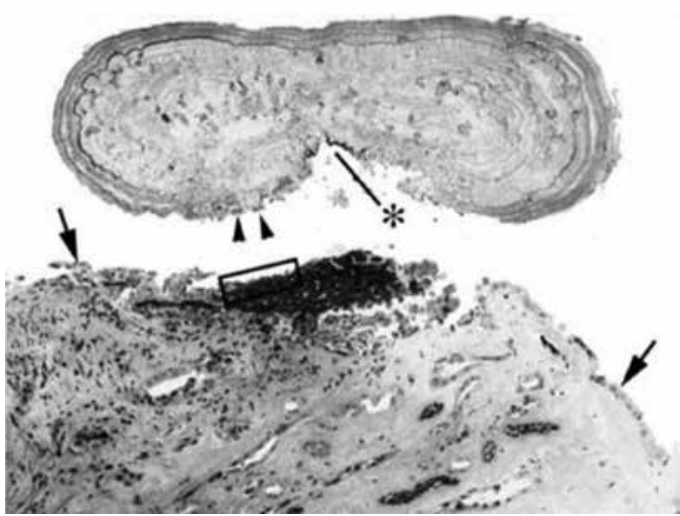

Şekil 6: Demineralizasyon sonrası taş-doku kompleksi. Taşın altındaki dokudan ayrılmış olduğuna dikkat ediniz (dikdörtgen kutu: Şekil 4'te detaylandırılmıştır). Bir miktar doku hala taş üzerindedir (asteriks). Ok başları hücresel debris bölgesini göstermektedir. Oklar papilla üzerinde hala ürotelyum kaplı alanları göstermekte iken

bu hücreler taş-doku bileşkesinde kaybolmuştur.

en az bir bölgede $\mathrm{CaP}$ alanları olduğunu ortaya koymuşlardır (15). Yazarlar sonuç olarak, serbest haldeki bir taşın iç kısmında $\mathrm{CaP}$ alanlarının belirlenmesini, o taşın bir zamanlar bir Randal plağına tutunmuş olduğunun kanıtı olarak yorumlanmıştır. X-1şını ile yapılan değerlendirmede de bu 9 taşın tamamının iç bölgelerinde apatit içerdiği gösterilmiştir (15).

Cifuentes ve ark.'ları da; spontan düşen idyopatik $\mathrm{CaOx}$ taşlarının da, dokuya tutunarak büyüdüklerine işaret eden küçük kalsifiye renal tubuller içeren bölgelere sahip olduklarını bildirmişlerdir (16). Yazarlar spontan olarak düşen 87 taşı elektron mikroskopik ve $X$ ışını dağılımlı element analizi yöntemi ile inceledikleri çalışmalarında, taşlarda daha önce dokuya yapışık olduklarını gösteren morfolojik özellikler belirlemişlerdir. $\mathrm{Bu}$ taşların $63^{\prime}$ ünün yüzeyinde plağa ait kanit varken, $13^{\prime}$ ünde de papilla ucuna ait olduğu düşünülen kalsifiye renal tubullere rastlanılmıştır (16). Bu çalışmalar bize idyopatik $\mathrm{CaOx}$ taş hastalarındaki böbrek içindeki serbest taşların da bir zamanlar Randal plaklarına tutunmuş oldukların, $\mathrm{CaOx}$ ile süpersatüre idrarın bu tutunma noktasını CaOx tabakası ile kapladığını ve mikro-BT ile gösterildiği gibi tutunma noktasının zamanla taşın iç kısımlarında kaldığını göstermektedir.

\section{Sonuç}

Yüksek idrar kalsiyum seviyesine, azalmış idrar hacmi ve pH'ina yanıt olarak oluşan Randal plakları CaOx taşlarının yaklaşık \%75'ini oluşturan, idyopatik $\mathrm{CaOx}$ taş hastalarında taş oluşum sürecinin ilk ve temel basamağıdır. Taş-plak ara yüzeyinin detaylı incelenmesi bize, papiller epitelin bütünlügünün bozulması ile plağın idrar ile temasa geçtiğini, bu andan itibaren taş oluşum sürecinin tekrar eden "kristalizasyon atakları" şeklinde devam ettiğini göstermektedir. Bu hasta grubunda papillaya tutunmuş olan taşların dokuya tutunma noktalarının Randal plakları olduğu net bir şekilde gösterilmiştir. Ek olarak, bu hastalarda toplayıcı sistemde serbest halde bulunan veya spontan olarak düşmüş taşların yüzeyinde ve/veya iç kısmında da bir zamanlar bir Randal plağına tutunmuş olduklarını gösteren kanıtlar ortaya konmuştur.

\section{Kaynaklar}

1. Pearle MS, Calhourn EA, Curhan GC Urologic diseases in America project: urolithiasis. J Urol; 2005; 173:848-57.

2. Evan AP. Physiopathology and etiology of stone formation in the kidney and the urinary tract. Pediatr Nephrol 2010; 25:831-4.

3. Randall A. The etiology of primary renal calculus. Int Abstr Surg 1940; 71:209-40.

4. Evan AP, Lingeman JE, Coe FL, Parks JH, Bledsoe SB, Shao Y, et al. 2003. Randall's plaque of patients with nephrolithiasis begins in basement membranes of thin loops of Henle. J Clin Invest 2003; 111:607-16.

5. Bulger RE, and Trump BF. Fine structure of the rat renal papilla. Am. J. Anat 1966; 118:685-96.

6. Asplin JR, Mandel NS, and Coe FL. Evidence for calcium phosphate supersaturation in the loop of Henle. Am J Physiol 1996; 270:F604-F613.

7. Evan AP, Coe FL, Gillen D, Lingeman JE, Bledsoe S, Worcester EM. Renal intraluminal crystals and hyaluronan staining occur in stone formers with bypass surgery but not with idiopathic calcium oxalate stones. Anat Rec 2008; 291:325-34.

8. Evan AP, Coe FL, Lingeman JE, Shao Y, Sommer AJ, Bledsoe SB et al. Mechanism of Formation of Human Calcium Oxalate Renal Stones on Randall's Plaque. The Anatomical Record 2007; 290:1315-23.

9. Evan AP, Lingeman JE, Coe FL, Parks JH, Bledsoe SB, Shao Y.Randall's plaque of patients with nephrolithiasis begins in basement membranes of thin loops of Henle. J Clin Invest 2003; 111:607-16.

10. Linnes MP, Krambeck AE, Cornell L, Williams Jr JC. Et al. Phenotypic characterization of kidney stone formers by endoscopic and histological quantification of intra-renal calcification. Kidney Int 2013; 84: 818-2.

11. Evan AP, Lingeman JE, Coe FL and Worcester E. Randall's plaque: Pathogenesis and role in calcium Oxalate nephrolithiasis. Kidney Int 2006; 69: 1313-8.

12. Kuo RL, Lingeman JE, Evan AP, Paterson RF, Parks $\mathrm{JH}$, Bledsoe SB, Munch LC, Coe FL. Urine calcium and volume predict coverage of renal papilla by Randall's plaque. Kidney Int 2003; 64:2150-4.

13. Evan AP, Lingeman JE, Coe FL et al. Crystal-associated nephropathy in patients with brushite nephrolithiasis. Kidney Int 2005; 67: 576-91.

14. Miller NL, Gillen DL, Williams JC, Evan AP, Bledsoe SB, Coe FL. A formal test of the hypothesis that idiopathic calcium oxalate stones grow on Randall's plaque. BJU Int 2009; 103: 966-71.

15. Miller NL, Williams JC, Evan AP, Bledsoe SB, Coe FL, Worcester EM et al. In Idiopathic Calcium Oxalate Stone Formers, Unattached Stones Show Evidence of Having Originated as Attached Stones on Randall's Plaque: A Micro CT Study. BJU Int 2010; 105: 242-5.

16. Cifuentes D L, Minon-Cifuentes JL, Medina JA. Papillary stones: calcified renal tubules in Randall's plaque. J Urol 1985; 133: 490-4.

Yazışma Adresi:

Tayfun Şahinkanat,

Kahramanmaraş Sütçüimam Üniversitesi, Üroloji AD, Kahramanmaraş

Tel: +90 5424352757

e-mail: tskanat@yahoo.com 